\title{
POLICE OFFICERS, AT-RISK-YOUTH AND COMMUNITY SAFETY PROJECT: A CASE STUDY OF THE SOUTHSIDE OF BELIZE CITY
}

\author{
Oscar S. MMBALI ${ }^{10}$ \\ DOI: 10.35782/JCPP.2020.3.02
}

Abstract: This study sought to answer the following questions: (1) What themes emerge out of the interactions between police officers and at-risk-youths? (2) What larger ramifications emerge from the study (if any)? The study found that at-risk-youth tend to fear and distrust the police but that fear fades away, confidence and trust in police officers is built, depending on the way police officers treat the youth in each situation. At-risk-youth saw the police in positive light when police officers played the role of the helper in the situation rather than the role of security agents. The study also found that since police officers have more power in their interaction with at-risk-communities, they influence and largely determine the realization of peaceful and inclusive communities. The study recommends investing in projects that bring together police officers and atrisk-communities to work for peaceful and inclusive societies. Building stronger relations between police officers and at-risk-communities requires intentional long-term policy commitment that provides opportunities for police work, especially community policing to be integrated into community development work.

Keywords: community; police; justice; inclusion; peace; development

\section{Introduction}

The Sustainable Development Goal 16 seeks to promote peaceful and inclusive societies for sustainable development, to provide access to justice for all and to build effective, accountable and inclusive institutions at all levels (UNDP, 2015). Achieving this goal in Belize means two things: (1) addressing the problem of gun-related violence; (2) improving the relationship between police officers and at-risk-communities, especially the youth. Focus on at-risk-youth is important because the youth provide the

\footnotetext{
${ }^{10}$ Dr., Belize City Friends Center, Belize; Email: mmbali76@gmail.com
} 
vulnerable pool of candidates from which organized crime groups recruit members. Focus on improving relations between youth and police officers is important because it contributes to the desired quality of policing practices and community safety.

The Southside of Belize city is among the poorest parts of the country. The city was established by the British during the 1600s. Slaves from West Africa were settled there to work in forestry as woodcutters. There were about 39,555 people of African descent, representing $69 \%$ of the city population, according to the 2010 census. The area is heavily congested with increasingly new informal houses attached to the original buildings. Most households are female headed, yet unemployment among women is $68.7 \%$ (Government of Belize, 2019).

Most of the reported crimes that occur on the Southside of Belize city are gang and gun-related. There are about 900 to 1,400 gang members in the city. About one in five youth in the city is exposed to gang activity. Gang networks operate in the community, schools and informal peer networks. Over $80 \%$ of gang members who have been studied reported that they had family members affiliated to gang organizations. Youth tend to join gangs at the ages of 13-16 years. They do so to seek protection, feel safe or revenge a killing or harm caused to them or to a family member. Youth who are often recruited into gangs are also associated with the following risk factors: (1) they come from broken homes; (2) they were suspended or expelled from school; (2) they dropped out of school; (4) they were not able to join high school or college because of poverty or other socio-economic related circumstances. Daily activities in the city are often interrupted by gang activities therefore limiting the freedom to conduct socio-economic activities. Many youths studied had experienced or witnessed gang related violence firsthand and were exposed to trauma (Inter-American Development Bank, 2019).

About $66 \%$ percent of young people on the Southside live below the poverty line. There is disproportionate contact between law enforcement and young men on the Southside (Peirce, 2017). This often creates police-community conflict. Youth violence in the Southside is attributed to factors that include drug trafficking, the presence of gangs, availability of illegal firearms, human trafficking, fragmentation of social ties, lack of education, lack of employment for youth, and failure to implement programs designed to help youth (Peirce \& Veyrat-Pontent, 2013). There is a disconnect between state security provisions and engaging vulnerable youths exposed to violence and victimization (Baird, 2013).

The traditional view of peace, security, justice, law and order assumes that government, having been entrusted with coercive power, legitimately applies that power to enforce peace (Pandit \& Basu, 2015). On the streets, the presence of government is embedded in the presence and work of the police. Studies show that police culture is rooted in the historical inclination to unfairly treat people of African, Asian, or other minority identity. Racist beliefs, xenophobic attitudes and prejudices are still entrenched in 
policing practices, even in places where the police service or force is diverse. Negative stereotypes are part of daily workplace talk in the justice system and inform the way police classify people because of their ethnic origin. For example, police officers tend to classify people of African or Asian origin as deviant, troublesome, hard to handle, suspicious, aggressive, riotous etc. This characterization by government agencies legitimizes stereotypes, derivative negative perception and the way people of the respective ethnic origin are treated during police encounters (Bowling \& Philips, 2003).

This study is guided by labeling theory which is based on the principle of symbolic interactionism. Labeling theory assumes that people tend to act or behave in accordance to the label imposed on them (Bachman \& Schutt, 2012). If someone is labelled a suspect for example, by authorities or public, others will treat that person as a suspect. In reaction, the person is likely to act in reciprocity to the way they were treated. The theory is used in this study as the lens through which data is analyzed. The assumption guiding the analysis is that labels imposed on at-risk-individuals influence the way those individuals are perceived, treated and the reactionary behavior they assume to survive the situation.

\section{The Project: Improving relations between police officers and at-risk-youth}

In September 2017, a young man was stopped by police officers on patrol while riding a bicycle in Belize City. The interaction turned into an altercation. The young man was arrested. The employer of the young man, concerned with the relationship between police officers and young people in the city, shared this experience in a community meeting at Belize City Friends Center. Belize City Friends Center is a non-profit faithbased organization involved in community development on the Southside of Belize city. The center engages in a range of development work, for example peace building, networking, and resource mobilization to address socio-economic problems affecting the community, such as hosting medical camps to improve general public health, or hosting legal clinics to increase access to justice and relief assistance.

The center, in response, started a community safety forum to invite community leaders to the discussion about the interaction between police officers and the youth. TV advertisements and talk shows were used to mobilize community voice about the issue. Community leaders who participated in the community safety forums formed a coalition that later met with the Commissioner of Police and Minister of Foreign Affairs and Home Affairs, who at the time supervised the police department. The meeting focused on concerns about policing on the Southside of Belize City and how to improve relations between police officers and at-risk youths. Among the resolutions of the meeting was a call to civil society organizations and the police department to start projects that could improve relations between police officers and at-risk-youth. 
Following the resolution, Belize City Friends Center and the Police department partnered to conduct a campaign against human trafficking. This project was meant to promote community safety by bringing together at-risk-youth and police officers to work on an issue of mutual concern. Police officers and at-risk-youth were both agents of change and it was anticipated that they would see and label each other as such. The study focused on the following questions: (1) What themes emerge out of the interactions between police officers and at-risk-youths? (2) What larger ramifications emerge from the study (if any)?

\section{Methodology}

The study took place during and after campaigns held in the fall of 2017, spring, summer and fall of 2018, spring, summer and fall of 2019. Participants in the study were police officers sent by the police department to take part in the campaign and community leaders who worked with at-risk-youth who volunteered to participate in the project.

Apart from literature review, data comes from what people say, feel, think or how they respond to a given situation under study (Loseke, 2013). Data was obtained from secondary sources such as research reports, oral accounts of incidents relevant to the study, problem centered key informant interviews, and participant observations. Problem centered key informant interviews are used to elicit information from informants when the researcher is seeking a deeper understanding of a subject. Questions are asked in a way that allows the informant the flexibility give a direct answer or tell a story (Witzel, 2000). Eight key informants participated in the study. They were interviewed about their experiences participating in a project where at-risk-youth interacted with police officers on a community project. Seeking oral narratives from participants enables the researcher to obtain data that entails the individual's personal reflection on the experience that is subject of the study (Creswell, 2013: 70-73).

Data analysis was based on hermeneutics - the idea that a text does not exist in a vacuum but as a response to something in the context where that text exists. In hermeneutics, the role of interpretation is to expose new ways of seeing the text, against the way the text has been usually understood (Fernandez 1967 in Bernard \& Ryan 2010, 257-258). Considering that the text here, is the interaction between police officers and at-risk-youths, which has often been incidental and negative, analysis in this study seeks to go beyond incidental encounters to incorporate intentional encounters between police officers and at-risk youths. It seeks to add voice to the discussion about making community policing a way of life, integrating community policing in the community's development vision, planning and work, in ways that make interaction between police officers and at-risk-youth a way of life-about issues of mutual concern. 


\section{Thematic Issues from the Project}

\section{(a) The fear of police officers}

From recruitment to the early stages of the project, at-risk youth involved in the project tended to fear and distrust the idea of coming to work with police officers on a community project. Community leaders who recruited youths to work with police officers on the project learned that many youths were afraid of coming near or into contact with police officers: "Them no good to we" (they are not good to us), one volunteer was told.

Some of the fears youth expressed about encounters with police officers were not as a result of the direct experiences of the individuals who shared them, but as a collective feeling shared in community. A few months before the campaign started, Kelvin, a form 6th student who had been very popular in the community because he was a DJ and a volunteer with the Department of Human Services, went missing after police raided his father's house. The incident sparked protests from hundreds of youths supported by rights groups. During the protests, there were unconfirmed reports from the speakers that he had been kidnapped by the police and was being secretly held. Kevin was later found and was brought to address the protests. He did not say where he was but he condemned the police raid. The incident was one among many that were shared in the community to explain why youths avoided police presence or encounters.

To bring youth to work together with police officers, community leaders spent time in community creating awareness of the importance of the project and encouraging young people to work with community organizations and police officers to address a critical peace and community safety issue like human trafficking. During the first phase of the campaign, forty-five youths turned up to participate in the project.

\section{(b) Confidence in working with police officers}

At-risk-youth developed confidence to positively engage and work with police officers after they saw the way police officers on the project treated them. Aware of the reservations the youths in the community had, community leaders decided to use sports as a mechanism to start the relations between youths and police officers. At the start of the campaign, the police department sent a team of cadets to participate in a basketball tournament with other six teams of at-risk youths from various areas of the Southside considered rival gang territories. The event began with all participants gathered in a large circle, followed by self-introductions, and an address from the host of the campaign. After this, the youths engaged in a community workshop led by a senior officer from the Police Training Academy. After the workshop, the youths regrouped into their teams and started basketball games. Apart from leading the workshop, others played the roles of the referees, while others cheered or provided aid to the participating teams. 
At the end of the games, there were more spontaneous interactions between the youth and the police officers. In the campaigns that followed, more youth teams from the community participated, after they learned from those who first attended the campaign, that the interactions between police officers and the youths were safe, communal and educative. The use of sports as a tool to initiate positive interactions between police officers and at-risk-youth proved not only effective, but also provided a practical experience on alternative ways to envision developing positive routine encounters between police officers and at-risk youth in the community.

\section{(c) Treatment of at-risk-youth during the project}

In one of the campaigns, the police department sent two police officers to talk to atrisk-youths about the status of human trafficking in Belize and what they could to do to help address the problem. Before they started talking about human trafficking, the officers first talked about their lived experiences growing up on the Southside, why they chose to join the police force, and the challenges they faced while they served. This approach to engaging with the youth triggered about 30 minutes of questions and answers. This was the longest time youths had engaged the officers by asking questions. The questions ranged from how to respond to different human trafficking scenarios to personal aspirations of youths like how one can join the police force.

At the end of the workshop, participants in the campaign went around the community and distributed flyers about human trafficking and conversing. Some youths engaged police officers at a nearby police checkpoint and shared with them about the human trafficking campaign project. The treatment of at-risk-youth evolved from that of a stranger to a core-worker. By sharing their personal experiences, the police officers no longer appeared strangers to the youths. The sharing made the youths see officers as relatable. It enabled the youths to envision police officers and police work in new, but most importantly positive ways.

\section{Concluding thoughts}

At-risk-youth tended to see the police in positive light when police officers played the role of the helper in the situation rather that the role of security agents. Police carry immense power, even in at-risk-communities. Therefore, the use of police power during police interactions largely influences relations between police and at-risk communities. During the project, the youths looked at the police officers for guidance and leadership. Intentional community development work, to create opportunities for police and members of at-risk communities to engage in meaningful development work in communities, will provide opportunities for integrating policing practices within the development framework of the community and the communities' way of life. Consolidating and sharing knowledge and action from such experiences will build a 
knowledge base for policy agenda setting to promote peaceful and inclusive societies for sustainable development.

\section{References}

Bachman, R., Schutt, R. K. (2012). Fundamentals of Research in Criminology and Criminal Justice ( $2^{\text {nd }}$ Edition). Los Angeles: SAGE.

Baird, A. (2013). UNDP: Analytical Report on Best Practices for Youth Engagement in the Caribbean to Promote a 'Shift to Better Citizen Security' Prevention, Participation and Potential. Available at URL: researchgate.net/publication/273568012_Analytical_Report_ on_Best_Practices_for_Youth_Engagement_in_the_Caribbean_to_

Promote_a_\%27Shift_to_Better_Citizen_Security\%27_Prevention_Participation_and_Pot ential, retrieved on: September 15th, 2018.

Bernard, H.R., \& Ryan, G.W. (2010). Analyzing Qualitative Data. Los Angeles: SAGE.

Bowling, B. \& Phillips, C. (2003). Policing ethnic minority communities. In: Newburn, T. (Ed.): Handbook of Policing (pp. 528-555). Willan Publishing, Devon.

Creswell J.W. (2013). Qualitative inquiry and research design: Choosing among five approaches (3 ${ }^{\text {rd }}$ edition). Thousand Oaks, CA: Sage.

Government of Belize (2019). Community Action for Public Safety II. Available at URL: http://humandevelopment.gov.bz/index.php/community-action-for-public-safety-2/, retrieved on: August 13th, 2020.

Inter-American Development Bank. (2019). Belize City Community Gang Assessment. Available at URL: https://www.iadb.org/en, retrieved on: August 20th, 2020.

Loseke, D. (2013). Methodological Thinking: Basic Principles of Social Research Design. Los Angeles: Sage.

Pandit, S. D. \& Basu, R. (2015). Cultural Conflicts in South East Asia: The Case of Preah Vihear. Journal of International Studies, 3(1\&2), 54-80.

Peirce, J. (2017). Gap Analysis Report: Citizen Security in Belize. Institutions for Development Sector Innovation in Citizen Services Division, Discussion Paper No IDB-DP-513. Available at URL: publications.iadb.org/handle/11319/8274, retrieved on: May 5th, 2018, DOI: http://dx.doi.org/10.18235/0000695.

Peirce, J. \& Veyrat-Pontet, A. (2013). Citizen Security in Belize. Inter-American Development Bank Institutional Capacity of the State (IFD/ICS), Technical Note No. IDB-TN-572. Available at URL: publications.iadb.org/handle/11319/6001, May 5th, 2018.

United Nations Development Program (UNDP). (2015). Sustainable Development Goals. Available at URL: https:/www.undp.org/content/undp/en/home/sustainable-developmentgoals.html, retrieved on August 13th, 2020.

Witzel, A. (2000). The problem-centered interview. FQS: Forum Qualitative Sozialforschung, 1(1), Art. 22. 